\title{
Can perineal tear be predicted by severity of striae gravidarum score?
}

\author{
Nidhi Patel $^{1}$, Nilesh Shah ${ }^{1 *}$, Gaurav Desai ${ }^{2}$
}

\begin{abstract}
${ }^{1}$ Department of Obstetrics and Gynecology, ${ }^{2}$ Department of Community Medicine, GMERS Medical College and Civil
\end{abstract} Hospital, Vadnagar, Gujarat, India

Received: 17 April 2019

Accepted: 16 May 2019

*Correspondence:

Dr. Nilesh Shah,

E-mail: nidhi301286@yahoo.co.in

Copyright: () the author(s), publisher and licensee Medip Academy. This is an open-access article distributed under the terms of the Creative Commons Attribution Non-Commercial License, which permits unrestricted non-commercial use, distribution, and reproduction in any medium, provided the original work is properly cited.

\begin{abstract}
Background: The objective of this study was to wether perineal tear predicted by scoring of severity of striae gravidarum. The objective of this study was to predict perineal tear by simple non-invasive method and help to prevent maternal morbidity.

Methods: Three hundred ninety four patients delivered normally were included in this study. Striae gravidarum score was assessed using the Atwal numerical scoring system. The association was examined between striae and perineal tear as the outcome measure, defined by tears or laceration, and the total striae scores (TSS) was obtained.

Results: In present study population mean age was 25.16 years ranging from 16-40, mean gravidity was 2.16 ranging from $1-8$, average baby birth weight was $2.713 \mathrm{~kg}$ ranging from $1.62-4.58$ The only predictors of perineal tears that were found to be statistically significant in our study were severity of striae gravidarum and episiotomy given or not. In patients with moderate to severe striae there was tear in 90 patients as compared to 29 patients with no or mild striae. 224 patients belonging to no or mild striae group delivered without any perineal tear whereas 51 patients in moderate to severe striae group delivered without tear. Out of these 51 patients 5 were given episiotomy. 2 patients who were given episiotomy had perineal tear as compared to 117 patients who were not given episiotomy. This shows that patients who had an episiotomy were less likely to have perineal tear in most cases.

Conclusions: This study demonstrates a significant relation between severity of striae gravidarum and perineal tear. The findings suggest that striae gravidarum assessment may be used in the clinical setting even by paramedical staff as a simple and noninvasive tool to better define women at risk for perineal tear.
\end{abstract}

Keywords: Birth Weight, Episiotomy, Perineal tear, Skin, Striae gravidarum

\section{INTRODUCTION}

Striae distensae are a common form of dermal scarring. Synonyms include the terms striae, stretch marks, and striae atrophicans. Striae gravidarum are striae distensae occurring secondary to pregnancy. These appear initially as red, and later, as white lines on the skin, representing scars of the dermis, and are characterized by linear bundles of collagen lying parallel to the surface of the skin, as well as eventual loss of collagen and elastin. The estimated prevalence of striae distensae range from 50 to $80 \% .^{1,2}$ The anatomical sites affected vary, with areas commonly affected including the abdomen, breasts, thighs and buttocks. ${ }^{3}$ The three maturation stages of striae include the acute stage (striae rubra), the sub-acute stage characterized by purpuric striae, and the chronic stage (striae alba). ${ }^{4}$ Although typically asymptomatic, striae distensae may be disfiguring and psychologically distressing to patients and remain an important target of research.

Striae gravidarum (SG) (stretch marks) observed during pregnancy that may be an indicator of poor skin elasticity. The type and amount of collagen in connective 
tissue are considered to determine the individual's elastic index. The skin surface is made up of a complex network of crossing thin lines. The two-dimensional relationship between primary and secondary lines determines the skin texture and its grade of irregularity. ${ }^{5,6}$ Striae gravidarum is caused by changes in the structural connective tissue due to a hormonal elect on the alignment and reduced elastin and fibrillin in the dermis. ${ }^{7}$

One who does not have stretch marks may have better skin elasticity and may be less likely to tear perineal and vaginal tissue during vaginal delivery. This study was conducted to determine whether striae gravidarum could predict lacerations and their severity. During a normal vaginal birth, the fetal head exerts significant pressure on the perineum. Some women seem to have tissue that tears easily, even with a small baby and apparently easy birth. Others will give birth over intact perineum in spite of large babies or unusual presentations. If the same midwife uses approximately the same perineal protection techniques with each birth but gets very different perineal outcomes, one must assume that there are other factors besides perineal management at work.

Perineal trauma is common during vaginal birth and can range from minor mucosal lacerations to severe injury that involves the musculature of the perineum and rectum. ${ }^{8}$ Perineal trauma complication are found to have a major negative effect on physical, psychological, social aspects and quality of life. Routine or restricted use of Episiotomy as an intervention to avoid perineal tear is debatable. ${ }^{9}$ Therefore, better prediction of women at risk for spontaneous perineal tear is needed to improve the outcome of vaginal childbirth. ${ }^{10}$

This correlational research will examine the contribution of a woman's connective tissue elasticity as a factor in maintaining an intact perineum during birth, using abdominal striae as the marker variable for connective tissue elasticity. It is important to investigate if there might be any relationship of skin type to perineal integrity, so as to help in making decisions regarding the woman's care during childbirth. This study was designed to identify factors for determining this and particularly whether abdominal striae gravidarum can predict the likelihood and severity of tear.

\section{METHODS}

We did a cross sectional study to test our hypothesis that those with few or no striae gravidarum are less likely to tear significantly. Three hundred ninety four patients delivered normally were included in this study, according to the following inclusion criteria: a) non-instrumental vaginal child birth b) term delivery c) singleton pregnancy. This observational cross sectional Study was performed for the period of six months from October 2018 to March 2019 in a GMERS, Vadnagar Medical College, Civil Hospital. All women were examined in the labour room. The assessment of striae gravidarum was performed by the trained sisters in all the women, who were blind to the information about whether the suturing had been performed.

Severity scoring of striae gravidarum was observed using the numerical scoring system of Atwal. ${ }^{11}$ This scale provides a rank based on observation of four areas in which SG is most commonly observed (abdomen, hips, buttocks, and breast) the scale comprises the following criteria (a) the number of striae gravidarum at each body site $(0=$ no striae signs, $1=1-4$ striae, $2=5-10$ striae, $3=$ more than 10 striae) and (b) the color of the striae gravidarum which ranges from pale to purple $(0=$ no redness, $1=$ pink, $2=$ dark red, $3=$ purple). The final score for each body site, relating to number and color, ranges from 0 to 6. Accordingly, the TSS (total striae score) for all four body sites ranges from 0 to 24 . Women having TSS score up to 12 were considered to be having mild striae, 13-18 TSS score indicated moderate striae and more than 18 TSS Score indicated severe striae. Later collected all medical, obstetric and demographic data from medical files. Included in the database were age, parity, perineal tear, episiotomy data were noted.

\section{Statistical analysis}

The data entered into Epi Info 7 statistical analysis software package and Chi- square test on the various risk factors and delivery outcomes was done. Variables statistically significant in predicting lacerations namely striae gravidarum score and episiotomy was analyzed.

\section{RESULTS}

In present study population mean age was 25.16 years ranging from $16-40$, mean gravidity was 2.16 ranging from $1-8$, average baby birth weight was $2.713 \mathrm{~kg}$ ranging from 1.62-4.58 (Table 1).

Table 1: Descriptive statistic for the study group ( $N=394)$.

\begin{tabular}{|llll|}
\hline Variable & Mean & $\begin{array}{c}\text { Standard } \\
\text { deviation }\end{array}$ & Range \\
\hline Age (years) & 25.16 & 3.74 & $16-40$ \\
\hline Gravidity & 2.16 & 1.14 & $1-8$ \\
\hline Baby weight $(\mathrm{kg})$ & 2.713 & 0.44 & $1.62-4.58$ \\
\hline
\end{tabular}

Figure 1 shows the categories of striae with no striae, mild striae, moderate striae and severe striae on the basis of score. It evident from figure that maximum patients $40.1 \%$ belonged to no striae group whereas $24.11 \%$ belonged to mild striae, $25.88 \%$ belonged to moderate striae, $9.89 \%$ belonged to severe striae.

Table 2 shows various factors associated with perineal tears. Variables are severity of striae, episiotomy (given or not) and baby weight were taken into consideration and their statistical significance was calculated. 


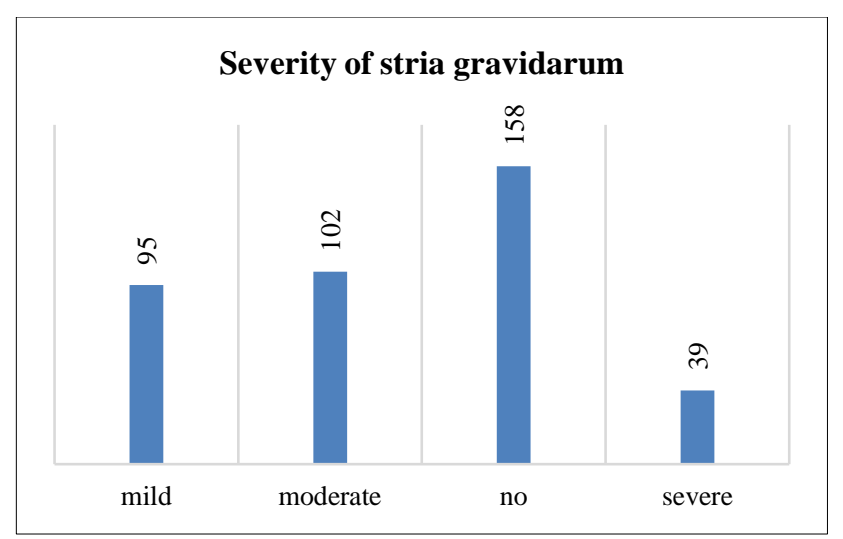

Figure 1: Severity of striae gravidarum according to striae score.
The only predictors of perineal tears that were found to be statistically significant in our study were severity of striae gravidarum.

Table 3 shows that out of all the patients of No or mild stria, perineal tear was absent in all the cases performed with episiotomy. In cases without episiotomy, perineal tear was present in $29 / 128$ cases. This difference was statistically not significant $(p>0.05)$. Out of all the patients of moderate or severe stria, perineal tear was absent in 5/7 cases performed with episiotomy. In cases without episiotomy, perineal tear was present in 88/134 cases. This difference was statistically not significant $(\mathrm{p}>0.05)$.

Table 2: Factors associated with perineal tear.

\begin{tabular}{|c|c|c|c|}
\hline Striae & No Perineal tear & Perineal tear & P value * \\
\hline No & 154 & 4 & \multirow{4}{*}{$<0.001$} \\
\hline Mild ( TSS upto 12 ) & 70 & 25 & \\
\hline Moderate (TSS 13-18) & 46 & 56 & \\
\hline Severe $(\mathrm{TSS}>18)$ & 5 & 34 & \\
\hline Baby weight (kg) & No Perineal tear & Perineal tear & \\
\hline$<=2$ & 16 & 1 & \multirow{7}{*}{0.16} \\
\hline 2 to 2.49 & 79 & 38 & \\
\hline 2.5 to 2.99 & 113 & 44 & \\
\hline 3 to 3.49 & 58 & 30 & \\
\hline 3.5 to 3.99 & 8 & 5 & \\
\hline 4 to 4.5 & 1 & 0 & \\
\hline$>=4.5$ & 0 & 1 & \\
\hline
\end{tabular}

Table 3: Episiotomy versus perineal tear according to severity of striae gravidarum.

\begin{tabular}{|lllll|}
\hline \multirow{2}{*}{ Perineal Tear } & No / mild striae & & Moderate / severe striae \\
\cline { 2 - 2 } & No episiotomy & Episiotomy & No episiotomy & Episiotomy \\
\hline Present & 199 & 25 & 46 & 5 \\
\hline P value* & 29 & 0 & 88 & 2 \\
\hline
\end{tabular}

* - Chi-square Test

Table 4: Episiotomy versus perineal tear.

\begin{tabular}{|c|c|c|c|}
\hline \multirow{2}{*}{ Episiotomy } & \multicolumn{2}{|c|}{ Perineal Tear } & \multirow{2}{*}{ P value* } \\
\hline & No & Yes & \\
\hline Given & 30 & 2 & \multirow{2}{*}{$<0.001$} \\
\hline Not given & 245 & 117 & \\
\hline
\end{tabular}

* - Chi-square Test

It is also observed that there is statistically significant correlation between perineal tear and severity of striae gravidarum. In patients with moderate to severe striae there was tear in 90 patients as compared to 29 patients with no or mild striae. Almost 224 patients belonging to no or mild striae group delivered without any perineal tear whereas 51 patients in moderate to severe striae group delivered without tear. Out of these 51 patients 5 were given episiotomy. 2 patients who were given 
episiotomy had perineal tear as compared to 117 patients who were not given episiotomy

\section{DISCUSSION}

Primary aim of this study was to determine whether Total Striae Score can be used as a predictor of perineal tear at the time of vaginal delivery. Therefore, total Striae Score can be used as an additional valuable predictor of the risk for perineal tear.

Striae gravidarum is common occurrence during pregnancy, though its severity is not considered as a medical condition in any clinical relevance for consideration in routine follow-up practice. It develops after 24 weeks of gestation. It has been reported that previous occurrence of striae on the breasts or thighs, family history of striae and race are significant predictors of striae development. ${ }^{6}$ Previous studies have demonstrated that maternal age, baseline and delivery BMI, neonatal birth weight, length and head circumference were independently associated with the occurrence of striae. ${ }^{11}$ Many factors have an impact on whether patients have perineal tears at the time of delivery. These factors are outlined in such as severity of striae, episiotomy (given or not given) and baby weight was taken into consideration and their statistical significance was calculated.

The only predictors of perineal tears that were found to be statistically significant in our study were severity of striae gravidarum and episiotomy given or not. In our study no statistically significant relation was found between baby weights with perineal tears. This observation does not correlate with the study conducted by Angioli and Gomez et al. ${ }^{12}$

It is also observed that there is statistically significant correlation between perineal tear and severity of striae gravidarum.

In patients with moderate to severe striae there was tear in 90 patients as compared to 29 patients with no or mild striae. 224 patients belonging to no or mild striae group delivered without any perineal tear whereas 51 patients in moderate to severe striae group delivered without tear. Out of these 51 patients 5 were given episiotomy. 2 patients who were given episiotomy had perineal tear as compared to 117 patients who were not given episiotomy. This shows that patients who had an episiotomy were less likely to have perineal tear in most cases.

In the past numerous controlled trials have compared outcomes in two groups - one in which episiotomy is given only for fetal or maternal indication or to prevent perineal tear. ${ }^{13-17}$ Still the use of liberal episiotomy to prevent perineal tear is debatable (Table 4). Previous research has shown that morbidity is higher in those with an episiotomy that in those without one. Any predictors that can help determine who can deliver without an episiotomy should be investigated to better guide physician in deciding who needs an episiotomy.

Several limitations in this study should be noted. First, the study was observational rather than an interventional design that may reduce the ability to emphasize the findings. Second data related to any previous episiotomy was missing in multiparae patients. Greater tendency to perform episiotomy in primigravida patients may limit the findings.

\section{CONCLUSION}

The foremost finding of our study is that an assessment of striae gravidarum appears to predict the occurrence of perineal tears. Striae score should be thus part of obstetrical assessment of the patients in the third trimester of pregnancy because such scores can be obtained with a simple and noninvasive observation. Paramedical staff in peripheral centers can also be trained to calculate the total striae score which can help them decide if episiotomy is to be given or not. Episiotomy definitely seems to be preventive for perineal tears but giving episiotomy for the same is still debatable as episiotomy in itself is associated with morbidity.

\section{Funding: No funding sources}

Conflict of interest: None declared

Ethical approval: The study was approved by the Institutional Ethics Committee

\section{REFERENCES}

1. Atwal GS, Manku LK, Griffiths CE. Striae gravidarum in primiparae. $\mathrm{Br} \mathrm{J}$ Dermatol. 2006;155:965-9.

2. Cho S, Park ES, Lee DH. Clinical features and risk factors for striae distensae in Korean adolescents. J Eur Acad Dermatol Venereol. 2006;20:1108-13.

3. Sisson WR. Colored striae in adolescent children. J Pediatr. 1954;45:520-30.

4. Kim BJ, Lee DH, Kim MN. Fractional photothermolysis for the treatment of striae distensae in asian skin. Am J Clin Dermatol. 2008;9:33-7.

5. Alves GF, Nogueira LS, Varella TC. Dermatology and pregnancy. Anias Brasilieros de Dermatologia. 2005;80:179-86.

6. Chang AL, Agrenado YZ, Kimball AB. Risk factors associated with striae gravidarum. J Am Acad Dermatol. 2004;51:881-5.

7. Osman H, Rubeiz N, Tamim H, Nassar AH. Risk factors for the development of striae gravidarum. Am J Obstet Gynecol. 2007;62:1-5.

8. Alves GF, Nogueira LS, Varella TC. Dermatology and pregnancy. Anias Brasilieros de Dermatologia. 2005;80:179-86.

9. Chang AL, Agrenado YZ, Kimball AB. Risk factors associated with striae gravidarum. J Am Acad Dermatol. 2004;51:881-5. 
10. Osman H, Rubeiz N, Tamim H, Nassar AH. Risk factors for the development of striae gravidarum. Am J Obstet Gynecol. 2007;62:1-5.

11. Atwal GS, Manku LK, Griffiths CE, Polson DW. Striae gravidarum in primiparae. $\mathrm{Br} \mathrm{J}$ Dermatol. 2006;155:965-9.

12. Angioli R, Gomez-Matin O, Cantuaria G, O’Sullivan MJ. Severe perineal lacerations during vaginal delivery: the University of Miami experience. Am J Obstet Gynecol. 2000;182:1083-5.

13. Klein MC, Gauthier RJ, Jorgensen SH, Robbins JM, Kaczorowski J, Johnson B, et al. Does episiotomy prevent perineal trauma and pelvic floor relaxation? Online J Curr Clin Trials. 1992;DocNo10:[6019 words; 65 paragraphs].

14. Helwig JT, Thorp JM, Bowes WA. Does midline episiotomy increase the risk of third- and fourth- degree lacerations in operative vaginal deliveries? Obstet Gynecol. 1993;82(2):276-9.

15. Thorp JM, Bowes WA, Brame RG. Selective use of midline episiotomy: effect on perineal trauma. Obstet Gynecol. 1987;70:240-4.

16. Gass MS, Dunn C, Stys SJ. Effect of episiotomy on the frequency of vaginal outlet lacerations. J Reprod Med. 1986;31(4):240-4.

17. Borghi J, Fox-Rushby J, Bergel E, Abalos E, Hutton G, Carroli G. The cost-effectiveness of routine versus restrictive episiotomy in Argentina. Am J Obstet Gynecol. 2002;186(2):221-8.

Cite this article as: Patel N, Shah N, Desai G. Can perineal tear be predicted by severity of striae gravidarum score?. Int J Reprod Contracept Obstet Gynecol 2019;8:2183-7. 